\title{
The effect of melatonin on circadian blood pressure in patients with type 2 diabetes and essential hypertension
}

Monika Możdżann ${ }^{1}$ Michał Możdżan², Maciej Chałubiński ${ }^{1}$, Katarzyna Wojdan ${ }^{1}$, Marlena Broncel ${ }^{1}$

${ }^{1}$ Department of Internal Medicine and Clinical Pharmacology, Medical University of Lodz, Poland

${ }^{2}$ University Teaching Hospital No. 2, Lodz, Poland

Submitted: 12 January 2012

Accepted: 11 May 2012

Arch Med Sci 2014; 10, 4: 669-675

DOI: $10.5114 /$ aoms.2014.44858

Copyright $\odot 2014$ Termedia \& Banach

\section{Abstract}

Introduction: The aim of this study was to evaluate the effect of melatonin on blood pressure in patients with essential hypertension receiving medical treatment and with type 2 diabetes in good metabolic control.

Material and methods: The study lasted 8 weeks. Patients were equipped with a 24-hour ambulatory blood pressure monitor and took melatonin ( $3 \mathrm{mg}$ a day in the evening) for 4 weeks. The patients were divided into four groups: group $1(n=32)$ including dippers, group $2(n=34)$ non-dippers treated with melatonin; and two control groups: group $3(n=28)$ including dippers and group $4(n=30)$ non-dippers treated without melatonin. After 4 weeks patients took melatonin for the next 4 weeks ( $5 \mathrm{mg}$ a day). In each visit were analyzed: systolic, diastolic and mean blood pressure in both day and night time.

Results: We observed that $29.5 \%$ non-dippers $(n=10)$ treated with melatonin in a dose of $3 \mathrm{mg} /$ day achieved features of dippers compared to control group $(p<0.05)$. Five $\mathrm{mg}$ of melatonin per day restored normal diurnal blood pressure rhythm in $32.4 \%$ non-dippers $(n=11, p<0.05)$. In non-dippers treated with melatonin significant decreases of diastolic, systolic and mean night blood pressure values $(p<0.05)$ were observed.

Conclusions: More than 30\% of non-dippers with type 2 diabetes treated with melatonin were restored to the normal circadian rhythm of blood pressure. The effect of melatonin in both doses ( $3 \mathrm{mg}$ and $5 \mathrm{mg}$ ) was significant for non-dippers only and included nocturnal systolic, diastolic and mean arterial pressure.

Key words: non-dipping, melatonin, ambulatory blood pressure monitoring.

\section{Introduction}

Melatonin is the primary hormone secreted by the pineal gland during the night. Melatonin plays an essential role in the regulation of the biological circadian rhythm. However, as a drug, it is not only used in restoring the normal circadian rhythm, but it can also be useful in preventive and anti-cancer therapies as well as in andropause symptoms relief [1-3].

In recent years, researchers have paid much more attention to the possibility of usage of melatonin in type 2 diabetes treatment. According to some studies, melatonin not only effectively lowers serum fasting glycemia, postprandial glycemia and glycated hemoglobin levels, but also has a positive effect on serum lipid profiles and the reduction of microalbuminuria [4-8]. Melatonin, acting through its receptors [9, 10], is

\author{
Corresponding author: \\ Monika Możdżan MD, PhD \\ Department of Internal \\ Medicine \\ and Clinical Pharmacology \\ Medical University of Lodz \\ $1 / 5$ Kniaziewicza St \\ 91-347 Lodz, Poland \\ Phone: +48695883154 \\ E-mail: monika.mozdzan@ \\ umed.lodz.pl
}


involved in numerous physiological processes, including blood pressure (BP) regulation. Therefore, considering its direct and indirect influence on $\mathrm{BP}$ regulation, it can be used as supporting treatment of hypertension.

In most cases, systolic and diastolic blood pressure (SBP and DBP) is higher during the day and lower during the night. Physiologically, the nocturnal decrease in BP should reach 10-20\% - such individuals are called dippers. Subjects with a night BP drop less than $10 \%$ are defined as non-dippers. Extreme dippers are individuals with a fall of nightly BP more than 20\% (measured as mean arterial pressure (MAP)).

The prognostic value of night-time BP has been found to be superior to the value of day-time BP [11]. Moreover, patients with a non-dipper circadian pattern of $\mathrm{BP}$, in which the nocturnal fall in $\mathrm{BP}$ is blunted or absent, are at higher risk of cerebroand cardiovascular complications [12, 13].

Numerous studies have shown that non-dippers have circadian disorder of melatonin secretion in comparison to dippers [14-16]. Additionally, they have nocturnal melatonin secretion diminished.

Proper antihypertensive therapy, including the principle of chronotherapy, should have beneficial effects not only on BP value, but also on circadian BP profile. A night pressure drop in the range of $10-20 \%$ and reduction of its morning increase have a positive influence on the progression of organ damage and reduce the number of adverse cardiovascular events [17-21].

We hypothesized that patients with the nondipper pattern would have lower serum melatonin concentrations as compared to dippers and melatonin supplementation may lead to a better antihypertensive effect. The aim of this study was to evaluate the effect of melatonin on BP in patients with essential hypertension receiving medical treatment and with type 2 diabetes in good metabolic control.

\section{Material and methods}

\section{Study group}

The study enrolled patients aged 40 to 60 years, with a body mass index (BMI) below $40 \mathrm{~kg} / \mathrm{m}^{2}$, suffering from type 2 diabetes at the stage of relative metabolic control of up to $7 \%$ of glycated hemoglobin $\left(\mathrm{HbA}_{1 \mathrm{c}}\right)$, treated with oral drugs, with coexisting hypertension treated pharmacologically.

Patients with daily glucose serum concentration

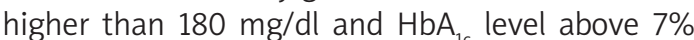
as well as individuals with BP values corresponding to grade III hypertension (RR values > 180/ $110 \mathrm{~mm} \mathrm{Hg}$ ) were not included in the study. Additional exclusion criteria were as follows: other types of diabetes, late microangiopathic complications of diabetes, secondary hypertension, sensitiv- ity to melatonin, mental illnesses, severe allergies, autoimmune diseases, cancer, addiction to alcohol and other chronic diseases requiring steroid intake, white coat hypertension, unstable coronary artery disease, cardiomyopathies, heart failure (III and IV NYHA), cancer, renal and hepatic failure, and hyperand hypokalemia. Last but not least, individuals working in night shifts or with sleeping disorders were not included in the investigation.

The research was carried out within 6 months, from April to September. The study lasted for 8 weeks. Patients were asked to arrive at the Department of Internal Medicine and Clinical Pharmacology, Medical University of Lodz (first visit) on an empty stomach in the morning. After a physical examination venous blood samples were taken for measurement of serum fasting glucose, $\mathrm{HbA}_{1 \mathrm{c}}$, alanine transaminase (ALT) and aspartate (AST), potassium, urea and creatinine. All individuals were weighed (0.1 kg accuracy) with the medical scale in order to calculate BMI. People who met the inclusion criteria during the first visit were equipped with a 24-hour ambulatory blood pressure monitor (ABPM) by Mobil-O-Graph's Margot Medical.

The BP was monitored for $24 \mathrm{~h}$ at home. Values were recorded every 20 min during the day and in 30-minute intervals at night. Patients were advised to perform their normal daily activities, while using ABPM. The time between 7 am-10 pm was considered as the day activity period, whereas hours between $10 \mathrm{pm}-7$ am were considered as the period of sleeping. On the next day, patients who reported to our department were qualified for participation in the study based on the results of laboratory tests and of ABPM. Individuals who had been qualified were instructed to take $3 \mathrm{mg}$ of melatonin per day orally (Melatonina, tab. 3 mg, Lek-AM, Poland) in the evening for a period of 4 weeks.

On the basis of night/day ratio of the nocturnal BP fall patients were divided into two groups: dippers and non-dippers. One group consisted of 60 subjects classified as dippers, and the second group consisted of 64 patients who were non-dippers. The characteristics of the study groups are shown in Table I.

Seventy-three out of all hypertensive patients received an antihypertensive drug. Remaining patients were treated with polytherapy. Over $50 \%$ of patients $(n=65)$ received only angiotensin-converting enzyme inhibitors (ACE inhibitors), and over 30\% of patients $(n=37)$ triple therapy. Angiotensin-converting enzyme inhibitors $(n=110)$ and diuretics ( $n$ = 61) were the most commonly used drugs (Table II).

Two control groups consisting of patients on current antihypertensive treatment, and two test groups in which melatonin treatment has been implemented in addition to the antihypertensive therapy were created. Group $1(n=32)$ included dippers treated with melatonin, whereas group 2 
Table I. Clinical characteristics of study population

\begin{tabular}{|lccc|}
\hline Parameters & Dippers $(n=60)$ & Non-dippers $(n=64)$ & $\begin{array}{c}\text { Statistical } \\
\text { significance } p\end{array}$ \\
\hline Age [years] & $47.4 \pm 12.1$ & $46.6 \pm 13.2$ & N/A \\
\hline Sex [female/male] & $33 / 27$ & $38 / 26$ & N/A \\
\hline Duration of type 2 diabetes [years] & $3.5 \pm 2.6$ & $3.7 \pm 2.7$ & N/A \\
\hline Duration of hypertension [years] & $4.2 \pm 3.0$ & $4.0 \pm 3.3$ & N/A \\
\hline BMI [kg/m²] & $32.9 \pm 3.2$ & $31.7 \pm 3.8$ & N/A \\
\hline Smokers in the study group [\%] & 35 & 33 & N/A \\
\hline Fasting glycemia, mean \pm SD [mg/dl] & $109.6 \pm 26.7$ & $113.2 \pm 22.7$ & N/A \\
\hline Postprandial glycemia, mean \pm SD [mg/dl] & $131.2 \pm 36.2$ & $136.1 \pm 30.1$ & $6.5 \pm 1.2$ \\
\hline HbA ${ }_{1 c}$ mean \pm SD [\%] & $6.3 \pm 1.1$ & &
\end{tabular}

Table II. Type of medical treatment among hypertensive patients with diabetes type 2

\begin{tabular}{|lcc|}
\hline Type of treatment & $\begin{array}{c}\text { Number of patients taking } \\
\text { a particular drug }\end{array}$ & $\begin{array}{c}\text { Percentage of patients taking } \\
\text { a particular drug }\end{array}$ \\
\hline ACE inhibitors & 110 & 89 \\
\hline ATIl-receptor antagonists & 17 & 14 \\
\hline Diuretics & 61 & 49 \\
\hline$\beta$-Blockers & 45 & 36 \\
\hline
\end{tabular}

$(n=34)$ consisted of non-dipper patients treated with melatonin. Both group 3 (a control group, $n=$ 28) including dippers and group 4 (a control group; $n=30$ ) consisting of non-dipper individuals were treated with antihypertensive therapy, and so far have not been given melatonin.

On the $2^{\text {nd }}$ visit after 4 weeks history was taken and medical examination was performed, glycemia and $\mathrm{HbA}_{1 \mathrm{c}}$ serum concentrations were assessed, and the ABPM was placed on the upper arms of patients. For the next 4 weeks patients took a higher dose of melatonin (5 mg a day) (Melatonina, tabl. $5 \mathrm{mg}$, Lek-AM, Poland). On the last visit $\left(3^{\text {rd }}\right)$ of the study after overall 8 weeks of melatonin administration the same procedures and checking as on the $2^{\text {nd }}$ visit were done.

Based on ABPM measurements mean values of the following were analyzed: SBP, DBP and MBP in both day and night time. Nocturnal decrease in BP (NSC\%) was analyzed according to the definition, and the possible change in belonging to dipper or non-dipper groups after treatment with melatonin was evaluated.

During the whole study patients did not have any changes in current treatment, e.g. new drugs administration, coming off any medicine and modification of drug doses being taken.

The study was approved by the Local Ethics Committee of the Medical University of Lodz, Poland.

\section{Statistical analysis}

For analyzed parameters measure of average and measure of dispersion (arithmetic means and standard deviations of BP values) were estimated. The distribution of values of studied parameters were compared with normal distribution using the $\chi^{2}$ test. For mean values before and after melatonin treatment comparison Student's $t$-test was used. Statistical analyses were performed using Statistica software.

\section{Results}

We observed that over $30 \%$ of non-dippers $(n=10)$ treated with melatonin in a dose of $3 \mathrm{mg} /$ day achieved dipper features. Five mg of melatonin per day restored normal diurnal BP rhythm in over $32 \%$ of non-dippers. In no individuals were excessive night BP falls over $20 \%$ observed, which indicates that none of the patients belonged to the extreme dippers (Table III).

In non-dippers treated with melatonin significant decreases of DBP, SBP and mean night blood pressure values were observed. There were no differences in changes of the above-mentioned parameters after treatment with melatonin in a dose of $5 \mathrm{mg}$ as compared to $3 \mathrm{mg}$ a day. In dippers we did not note any DBP, SBP or MBP falls both in $3 \mathrm{mg}$ and $5 \mathrm{mg}$ daily dose of melatonin (Table IV). 
Table III. Classification to dipper/non-dipper group in melatonin-treated patients and in control group

\begin{tabular}{|c|c|c|c|c|}
\hline & & Visit I & Visit II & Visit III \\
\hline \multirow{2}{*}{$\begin{array}{l}\text { All patients who received } \\
\text { melatonin } \\
n=66 \\
\text { (group } 1+\text { group } 2 \text { ) }\end{array}$} & $\begin{array}{c}\text { Percentage of dippers in all melatonin- } \\
\text { treated patients }\end{array}$ & $48 \%$ & $64 \% *$ & $65 \% *$ \\
\hline & $\begin{array}{l}\text { Number of melatonin-treated patients } \\
\text { dippers/non-dippers }\end{array}$ & $32 / 34$ & $42 / 24$ & $43 / 23$ \\
\hline \multirow{2}{*}{$\begin{array}{l}\text { All patients who did not } \\
\text { receive melatonin } \\
n=58 \\
\text { (group } 3+\text { group } 4 \text { ) }\end{array}$} & $\begin{array}{l}\text { Percentage of dippers in all melatonin } \\
\text { non-treated patients }\end{array}$ & $48 \%$ & $52 \%$ & $50 \%$ \\
\hline & $\begin{array}{l}\text { Number of melatonin non-treated } \\
\text { dipper/non-dippers patients }\end{array}$ & $28 / 30$ & $30 / 28$ & 29/29 \\
\hline
\end{tabular}

${ }^{*} v S . V I p<0.05$

Similarly, in both control groups we did not observe any significant differences in SBP, DBP or MBP values after both 4 and 8 weeks of the study period $(p>0.05)$ (Table V).

In non-dippers treated with melatonin both in $3 \mathrm{mg}$ and $5 \mathrm{mg}$ daily doses BP night falls were observed without significant differences between doses. In dipper patients melatonin did not affect night fall of BP as well as SBP, DBP and MAP. In dipper and non-dipper control groups there were not observed differences of night BP fall before 4 and 8 weeks of study (Table VI).

Table IV. Average daily and night blood pressure values in dipper and non-dipper groups before and after 4 weeks of melatonin treatment in a dose of $3 \mathrm{mg}$ and 8 weeks of melatonin treatment in a dose of $5 \mathrm{mg}$

\begin{tabular}{|c|c|c|c|c|c|c|c|}
\hline \multirow{2}{*}{\multicolumn{2}{|c|}{ Blood pressure values }} & \multicolumn{2}{|c|}{$\begin{array}{l}\text { Visit I } \\
\text { Before melatonin treatment }\end{array}$} & \multicolumn{2}{|c|}{$\begin{array}{c}\text { Visit II } \\
\text { After } 4 \text { weeks } \\
\text { of dose } 3 \mathrm{mg} \text { melatonin } \\
\text { treatment }\end{array}$} & \multicolumn{2}{|c|}{$\begin{array}{c}\text { Visit III } \\
\text { After } 4 \text { weeks } \\
\text { of dose } 5 \mathrm{mg} \text { melatonin } \\
\text { treatment }\end{array}$} \\
\hline & & $\begin{array}{l}\text { Daily blood } \\
\text { pressure } \\
\text { values }\end{array}$ & $\begin{array}{l}\text { Night blood } \\
\text { pressure } \\
\text { values }\end{array}$ & $\begin{array}{c}\text { Daily blood } \\
\text { pressure } \\
\text { values }\end{array}$ & $\begin{array}{l}\text { Night blood } \\
\text { pressure } \\
\text { values }\end{array}$ & $\begin{array}{l}\text { Daily blood } \\
\text { pressure } \\
\text { values }\end{array}$ & $\begin{array}{c}\text { Night blood } \\
\text { pressure } \\
\text { values }\end{array}$ \\
\hline \multirow{2}{*}{$\begin{array}{l}\text { SBP } \\
{[\mathrm{mm} \mathrm{Hg}]}\end{array}$} & Dippers & $144.2 \pm 14.6$ & $127.7 \pm 13.9$ & $143.7 \pm 12.3$ & $128.8 \pm 11.4$ & $142.8 \pm 12.5$ & $127.0 \pm 10.9$ \\
\hline & $\begin{array}{l}\text { Non- } \\
\text { dippers }\end{array}$ & $143.3 \pm 12.9$ & $133.9 \pm 13.1$ & $141.2 \pm 10.7$ & $130.3 \pm 10.9^{*}$ & $140.7 \pm 11.5$ & $129.8 \pm 9.8^{*}$ \\
\hline \multirow{2}{*}{$\begin{array}{l}\text { DBP } \\
{[\mathrm{mm} \mathrm{Hg}]}\end{array}$} & Dippers & $88.9 \pm 12.2$ & $74.1 \pm 11.3$ & $87.6 \pm 12.5$ & $73.9 \pm 12.1$ & $87.2 \pm 8.8$ & $73.3 \pm 8.5$ \\
\hline & $\begin{array}{c}\text { Non- } \\
\text { dippers }\end{array}$ & $86.8 \pm 11.0$ & $78.7 \pm 9.5$ & $86.2 \pm 10.6$ & $75.7 \pm 11.2^{*}$ & $85.7 \pm 9.6$ & $75.2 \pm 6.8^{*}$ \\
\hline \multirow{2}{*}{$\begin{array}{l}\text { MAP } \\
{[\mathrm{mm} \mathrm{Hg}]}\end{array}$} & Dippers & $108.5 \pm 18.3$ & $92.2 \pm 12.4$ & $106.9 \pm 12.3$ & $90.7 \pm 12.1$ & $106.4 \pm 12.6$ & $91.1 \pm 9.8$ \\
\hline & $\begin{array}{l}\text { Non- } \\
\text { dippers }\end{array}$ & $107.2 \pm 12.1$ & $98.0 \pm 13.1$ & $108.8 \pm 12.5$ & $95.2 \pm 8.9^{\star}$ & $109.3 \pm 13.1$ & $94.7 \pm 10.2^{*}$ \\
\hline
\end{tabular}

Table V. Average daily and night blood pressure values in dipper and non-dipper control groups before the study, after 4 weeks and 8 weeks of observation

\begin{tabular}{|c|c|c|c|c|c|c|c|}
\hline \multicolumn{2}{|c|}{ Blood pressure values } & \multicolumn{2}{|c|}{ Visit I at beginning of study } & \multicolumn{2}{|c|}{$\begin{array}{c}\text { Visit II after } 4 \text { weeks of } \\
\text { observation }\end{array}$} & \multicolumn{2}{|c|}{$\begin{array}{c}\text { Visit III after } 8 \text { weeks of } \\
\text { observation }\end{array}$} \\
\hline & & $\begin{array}{c}\text { Daily blood } \\
\text { pressure } \\
\text { values }\end{array}$ & $\begin{array}{l}\text { Night blood } \\
\text { pressure } \\
\text { values }\end{array}$ & $\begin{array}{l}\text { Daily blood } \\
\text { pressure } \\
\text { values }\end{array}$ & $\begin{array}{l}\text { Night blood } \\
\text { pressure } \\
\text { values }\end{array}$ & $\begin{array}{c}\text { Daily blood } \\
\text { pressure } \\
\text { values }\end{array}$ & $\begin{array}{c}\text { Night blood } \\
\text { pressure } \\
\text { values }\end{array}$ \\
\hline \multirow{2}{*}{$\begin{array}{l}\text { SBP } \\
{[\mathrm{mm} \mathrm{Hg}]}\end{array}$} & Dippers & $146.7 \pm 15.8$ & $128.3 \pm 14.7$ & $144.9 \pm 13.6$ & $126.2 \pm 14.2$ & $144.6 \pm 16.3$ & $128.3 \pm 15.6$ \\
\hline & $\begin{array}{c}\text { Non- } \\
\text { dippers }\end{array}$ & $142.9 \pm 16.1$ & $134.3 \pm 15.3$ & $144.5 \pm 13.9$ & $133.9 \pm 14.6$ & $143.9 \pm 11.7$ & $133.6 \pm 14.3$ \\
\hline \multirow{2}{*}{$\begin{array}{l}\text { DBP } \\
{[\mathrm{mm} \mathrm{Hg}]}\end{array}$} & Dippers & $91.1 \pm 14.3$ & $75.3 \pm 15.4$ & $89.3 \pm 13.7$ & $75.0 \pm 12.7$ & $89.0 \pm 11.9$ & $75.1 \pm 14.3$ \\
\hline & $\begin{array}{l}\text { Non- } \\
\text { dippers }\end{array}$ & $88.2 \pm 12.7$ & $81.4 \pm 11.7$ & $90.4 \pm 14.2$ & $80.2 \pm 14.3$ & $88.1 \pm 13.1$ & $79.1 \pm 13.9$ \\
\hline \multirow{2}{*}{$\begin{array}{l}\text { MAP } \\
{[\mathrm{mm} \mathrm{Hg}]}\end{array}$} & Dippers & $110.1 \pm 17.1$ & $92.1 \pm 12.4$ & $108.3 \pm 15.2$ & $91.2 \pm 15.4$ & $108.2 \pm 14.0$ & $92.2 \pm 14.7$ \\
\hline & $\begin{array}{l}\text { Non- } \\
\text { dippers }\end{array}$ & $105.2 \pm 14.3$ & $99.7 \pm 13.1$ & $103.6 \pm 13.7$ & $98.8 \pm 12.4$ & $104.3 \pm 12.1$ & $98.4 \pm 13.8$ \\
\hline
\end{tabular}

$S B P$ - systolic blood pressure, DBP - diastolic blood pressure, MAP - mean arterial pressure 
Table VI. Average night blood pressure fall in dipper and non-dipper melatonin-treated patients and in control patients

\begin{tabular}{|lcccccc|}
\hline & \multicolumn{2}{c}{ Visit I } & \multicolumn{2}{c|}{ Visit II } & \multicolumn{2}{c|}{ Visit III } \\
\cline { 2 - 7 } & Dippers & Non-dippers & Dippers & Non-dippers & Dippers & Non-dippers \\
\hline Melatonin-treated patients & $15.7 \pm 3.6$ & $8.5 \pm 2.2$ & $16.5 \pm 4.2$ & $12.3 \pm 4.2^{*}$ & $17.4 \pm 4.1$ & $13.1 \pm 5.1^{*}$ \\
\hline Control groups & $17.3 \pm 3.2$ & $8.1 \pm 3.6$ & $15.3 \pm 4.2$ & $7.8 \pm 3.2$ & $16.6 \pm 5.1$ & $8.5 \pm 6.1$ \\
\hline
\end{tabular}

Ninety-eight percent of patients $(n=122)$ successfully completed the study. Two melatonin nontreated patients did not finish the study because of family reasons, independently of their health status. During the study we did not note any adverse events associated with melatonin treatment. We also did not observe any elevations of BP values that might have caused a need of additional antihypertensive drugs administration or an increase in dosage of existing treatment. Fasting and postprandial glycemia as well as $\mathrm{HbA}_{1 \mathrm{c}}$ serum concentrations did not differ after 4 and 8 weeks of study between melatonin-treated patients and control groups.

\section{Discussion}

The results of experimental studies suggested that melatonin regulates values of BP multidirectionally. On one hand, it displays antioxidant properties, being an acceptor of free radicals, and maintains proper concentrations of nitrogen oxide (NO) - a strong vasodilator. On the other hand, it improves function of endothelium and reduces the activity of the adrenergic system. The hypotensive effect of melatonin occurs through the stimulation of melatonin receptors located in peripheral vessels and structures of the central nervous system, responsible for BP regulation [22]. Most studies showing the positive impact of melatonin on values of BP were carried out on animal models [23-27].

The results of our study demonstrate that melatonin in both 3 and $5 \mathrm{mg}$ daily doses did not reduce the value of the BP in dippers with diabetes type 2. However, in non-dippers a significant hypotensive effect as well as a decrease of night SBP, night DBP and night average BP were observed. It also demonstrates the lack of impact of a $5 \mathrm{mg}$ dose of melatonin on greater reduction of night SBP, DBP and MAP as compared to the dose of $3 \mathrm{mg}$ in non-dippers. One should admit that the obtained reduction of BP after melatonin treatment is not as spectacular as observed after the common hypotensive medicines. However, as clinical studies have shown, even a minimal decrease in $B P$ in $A B P M$ is associated with a significant reduction of cardiovascular complications [28, 29].

We observed an increase in the difference between day/night periods of BP with an average of
$9 \mathrm{~mm} \mathrm{Hg}$ to more than $13 \mathrm{~mm} \mathrm{Hg}$ after 4 weeks of melatonin application in the dose of $3 \mathrm{mg}$, and for more than $15 \mathrm{~mm} \mathrm{Hg}$ after applying melatonin in the dose of $5 \mathrm{mg}$ in non-dippers. As the results of our studies have shown, the use of a larger dose of melatonin did not cause any larger decrease of night BP as compared to the dose of $3 \mathrm{mg}$. There have been no significant changes in the night BP decrease among dippers treated with melatonin. The use of melatonin in the dose of $3 \mathrm{mg}$ contributed to changes of the class from non-dippers to dippers among 30\% of patients. The change of the dose of melatonin to $5 \mathrm{mg}$ slightly increased the percentage to $32 \%$. In conclusion, as can be seen from the analysis of our research, non-dippers reaped further benefit from the application of melatonin, because in this group of patients greater reduction of nightly BP was observed.

No study has aimed to analyze the impact of melatonin on BP values, average values of the nightly decrease of BP among patients with hypertension and co-existing diabetes type 2 . Only single studies have been carried out, which have proved a beneficial impact of melatonin on the 24-hour profile of BP among non-dippers by reduction of the BP and a change of affinity of patients from the non-dipper to the dipper group. These studies did not aim only at patients with diabetes type 2 and did not focus on comparison of various doses of melatonin [30].

The study of Cui et al. [31] evaluated the concentration of melatonin secreted by the pineal gland and changes of BP during $24 \mathrm{~h}$. The observation included two groups of patients with hypertension - dippers and non-dippers. In patients during the 24-hour ABPM, the concentrations of 6-sulfatoxymelatonin (SMT), a metabolite of melatonin in urine, examined during the day and night, were assessed. Nightly concentrations of SMT were substantially higher as compared to the values measured during the day time in all tested groups. The authors observed the lowest SMT levels at night and an SMT nightly/SMT daily rate reduction in the non-dipper group as compared to both dippers and controls. Moreover, a positive correlation between the values of the SMT nightly/SMT daily rate and reduction of BP was observed. This suggests that non-dippers 
retained a proper daily rhythm of melatonin secretion, i.e. they had lower levels of melatonin throughout the day than through the night. However, melatonin release during the night was reduced. Therefore, the decrease of BP values was weaker at night.

Cagnacci et al. [32] found that prolonged melatonin administration may improve the day-night rhythm of BP, particularly in women with blunted nocturnal decline. Grossman et al. [33] obtained similar results in reverse dippers. Melatonin treatment reduced nocturnal systolic and diastolic BP significantly, whereas placebo had no effect. This finding suggests that the addition of melatonin in a dose of $2 \mathrm{mg}$ at night to stable antihypertensive treatment may improve nocturnal BP control in patients with nocturnal hypertension.

The predictive value of the night-time BP in cardiovascular risk assessment is better than the value of daily BP [34]. The influence of melatonin treatment on night BP may bring benefit among patients with high cardiovascular risk of death [35]. Taking melatonin at evening hours appears to be favorable in reduction of $\mathrm{BP}$ in the early morning hours when a high BP level may lead to a cardiovascular event $[36,37]$.

The etiology of primary hypertension is not fully described, and it commonly has many causes, which requires combined therapy using different mechanisms of BP regulation. Melatonin can be used as an effective supporting therapy among patients with hypertension, who have shown a reduction of melatonin concentration. The most important observation of our work which may involve a broad, efficacious use of melatonin in the future in daily medical practice, in the view of the easier access to ABPM, is to obtain a substantial hypertensive effect among non-dipper patients who suffer from diabetes and hypertension as a result of its supplementation.

The group of patients with lower initial levels of melatonin who take melatonin supplementation reaches its correct concentrations, thus achieving a better effect. Our observations may at least partially answer the question why melatonin shows hypotensive activity among all patients included in the study. Probably only in cases of hypertension worsened by impaired melatonin release and reduced serum levels may melatonin taken orally support an effective hypertensive treatment.

Final understanding of the impact of melatonin on the value of $\mathrm{BP}$ requires future clinical studies. These studies should answer many questions concerning, e.g. determination of the influence of other melatonin doses besides $3 \mathrm{mg}$ and $5 \mathrm{mg}$ and another method of the medicine application within $24 \mathrm{~h}$ in order to reduce the value of BP values. Besides, we still do not know whether there are pharmacokinetic and pharmacodynamic interactions between melatonin and antihypertensive medicines and other preparations, not only antidiabetic, and whether the presence of other chronic diseases including diabetes has any significance in the regulation of hypertension among patients using melatonin.

This is a prospective study with short duration and a relatively small number of patients in each group. We concluded that non-dippers have lower concentrations of melatonin as compared to dippers, which could not be demonstrated in our tests without determining the concentration of melatonin.

In conclusion, more than $30 \%$ of non-dippers with type 2 diabetes treated with melatonin at a dose of $3 \mathrm{mg}$ were restored to the normal circadian rhythm of BP. However, the difference between the dose of $3 \mathrm{mg}$ and $5 \mathrm{mg}$ was not significant. The hypotensive effect of melatonin in both doses ( $3 \mathrm{mg}$ and $5 \mathrm{mg}$ ) is significant for non-dippers only and includes nocturnal systolic, diastolic and mean arterial pressure. Melatonin may support an effective hypertensive treatment.

\section{References}

1. Sánchez-Barceló EJ, Mediavilla MD, Tan DX, Reiter RJ. Clinical uses of melatonin: evaluation of human trials. Curr Med Chem 2010; 17: 2070-95.

2. Reiter RJ, Korkmaz A. Clinical aspects of melatonin. Saudi Med J 2008; 29: 1537-47.

3. Mediavilla MD, Sanchez-Barcelo EJ, Tan DX, Manchester L, Reiter RJ. Basic mechanisms involved in the anti-cancer effects of melatonin. Curr Med Chem 2010; 17: 4462-81.

4. Peschke E, Mühlbauer E. New evidence for a role of melatonin in glucose regulation. Best Pract Res Clin Endocrinol Metab 2010; 24: 829-41.

5. Mulder H, Nagorny CL, Lyssenko V, Groop L. Melatonin receptors in pancreatic islets: good morning to a novel type 2 diabetes gene. Diabetologia 2009; 52: 1240-9.

6. Gumustekin M, Tekmen I, Guneli E, et al. Short-term melatonin treatment improved diabetic nephropathy but did not affect hemorheological changes in diabetic rats. Pharmazie 2007; 62: 693-869.

7. Hussain SA, Khadim HM, Khalaf BH, Ismail SH, Hussein KI, Sahib AS. Effects of melatonin and zinc on glycemic control in type 2 diabetic patients poorly controlled with metformin. Saudi Med J 2006; 27: 1483-8.

8. Kadhim HM, Ismail SH, Hussein KI, et al. Effects of melatonin and zinc on lipid profile and renal function in type 2 diabetic patients poorly controlled with metformin. J Pineal Res 2006; 41: 189-93.

9. Nosjean O, Ferro M, Coge F, et al. Identification of the melatonin-binding site MT3 as the quinone reductase 2. J Biol Chem 2000; 275: 31311-7.

10. Dubocovich ML, Rivera-Bermudez MA, Gerdin MJ, Masana MI. Molecular pharmacology, regulation and function of mammalian melatonin receptors. Front Biosci 2003; 8: d1093-108.

11. Sega R, Facchetti R, Bombelli $M$, et al. Prognostic value of ambulatory and home blood pressure compared 
with office blood pressure in the general population: follow-up results from the PAMELA study. Circulation 2005; 111: 1777-83.

12. Coleman CT, Stowasser M, Jenkins C, Marwick TH, Sharman JE. Central hemodynamics and cardiovascular risk in nondippers. J Clin Hypertens 2011; 13: 557-62.

13. Możdżan M, Wierzbowska-Drabik K, Kurpesa $M$, et al. Echocardiographic indices of left ventricular hypertrophy and diastolic function in hypertensive patients with preserved LVEF classified as dippers and non-dippers. Arch Med Sci 2013; 9: 268-75.

14. Zeman M, Dulkova K, Bada V, Herichova I. Plasma melatonin concentrations in hypertensive patients with the dipping and non-dipping blood pressure profile. Life Sci 2005; 76: 1795-803.

15. Jonas M, Garfinkel D, Zisapel N, Laudon M, Grossman E. Impaired nocturnal melatonin secretion in non-dipper hypertensive patients. Blood Press 2003; 12: 19-24.

16. Mansoor GA. Sleep actigraphy in hypertensive patients with the 'non-dipper' blood pressure profile. J Hum Hypertens 2002; 16: 237-42.

17. O'Brien E, Sheridan J, O'Malley K. Dippers and non-dippers. Lancet 1988; 2: 397.

18. Casiglia E, Palatini P, Colangeli G, et al. 24 h rhythm of blood pressure and forearm peripheral resistance in normotensive and hypertensive subjects confident to bed. J Hypertens 1996; 14: 47-52.

19. Verdecchia P, Porcellati C, Schillaci G, et al. Ambulatory blood pressure. An independent predictor of prognosis in essential hypertension. Hypertension 1994; 24: 793-801.

20. Ohkubo T, Imai Y, Tsuji I, et al. Relation between nocturnal decline in blood pressure and mortality. The Ohasama Study. Am J Hypertens 1997; 10: 1201-7.

21. Tsioufis C, Andrikou I, Thomopoulos C, Syrseloudis D, Stergiou G, Stefanadis C. Increased nighttime blood pressure or nondipping profile for prediction of cardiovascular outcomes. J Hum Hypertens 2011; 25: 281-93.

22. Simko F, Paulis L. Melatonin as a potential antihypertensive treatment. J Pineal Res 2007; 42: 319-22.

23. Tain YL, Huang LT, Lin IC, Lau YT, Lin CY. Melatonin prevents hypertension and increased asymmetric dimethylarginine in young spontaneous hypertensive rats. J Pineal Res 2010; 49: 390-8.

24. Reiter RJ, Tan DX, Paredes SD, Fuentes-Broto L. Beneficial effects of melatonin in cardiovascular disease. Ann Med 2010; 42: 276-85.

25. Rezzani R, Porteri E, De Ciuceis C, et al. Effects of melatonin and Pycnogenol on small artery structure and function in spontaneously hypertensive rats. Hypertension 2010; 55: 1373-80.

26. Ersahin M, Sehirli O, Toklu HZ, et al. Melatonin improves cardiovascular function and ameliorates renal, cardiac and cerebral damage in rats with renovascular hypertension. J Pineal Res 2009; 47: 97-106.

27. Xia CM, Shao CH, Xin L, et al. Effects of melatonin on blood pressure in stress-induced hypertension in rats. Clin Exp Pharmacol Physiol 2008; 35: 1258-64.

28. Weber MA. The 24-hour blood pressure pattern: does it have implications for morbidity and mortality? Am J Cardiol 2002; 89: 27A-33A.

29. Khattar RS, Swales JD, Banfield A, Dore C, Senior R, Lahiri A. Prediction of coronary and cerebrovascular morbidity and mortality by direct continuous ambulatory blood pressure monitoring in essential hypertension. Circulation 1999; 100: 1071-6.

30. Rechciński T, Trzos E, Wierzbowska-Drabik K, Krzemińska-Pakuła M, Kurpesa M. Melatonin for nondippers with coronary artery disease: assessment of blood pressure profile and heart rate variability. Hypertens Res 2010; 33: 56-61.

31. Cui HW, Zhang ZX, Gao MT, Liu Y, Su AH, Wang MY. Circadian rhythm of melatonin and blood pressure changes in patients with essential hypertension. Zhonghua Xin Xue Guan Bing Za Zhi 2008; 36: 20-3.

32. Cagnacci A, Cannoletta M, Renza A, Baldassari F, Arangino S, Volpe A. Prolonged melatonin administration decreases nocturnal blood pressure in women. Am J Hypertens 2005; 18: 1614-8.

33. Grossman E, Laudon M, Yalcin R, et al. Melatonin reduces night blood pressure in patients with nocturnal hypertension. Am J Med 2006; 119: 898-902.

34. Chrusciel P, Goch A, Banach M, Mikhailidis DP, Rysz J, Goch JH. Circadian changes in the hemostatic system in healthy men and patients with cardiovascular diseases. Med Sci Monit 2009; 15: RA203-208.

35. Staessen JA, Thijs L, Fagard R, et al. Predicting cardiovascular risk using conventional $\mathrm{v} / \mathrm{s}$ ambulatory blood pressure in older patients with systolic hypertension. Systolic Hypertension in Europe Trial Investigators. JAMA 1999; 282: 539-46.

36. Stergiou GS, Vemmos KN, Pliarchopoulou KM, Synetos AG, Roussias LG, Mountokalakis TD. Parallel morning and evening surge in stroke onset, blood pressure, and physical activity. Stroke 2002; 33: 1480-6.

37. Filippatos TD, Rizos EC, Gazi IF, et al. Differences in metabolic parameters and cardiovascular risk between American Diabetes Association and World Health Organization definition of impaired fasting glucose in European Caucasian subjects: a cross-sectional study. Arch Med Sci 2013; 9: 788-95. 